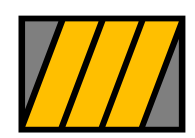

ESCUELA DE NEGocios Universidad Torcuato Di Tella centro de investigación en finanzas

Documento de Trabajo 06/2010

\title{
Global Financial Safety Nets: Where Do We Go from Here?
}

\author{
Eduardo Fernández-Arias \\ Inter-American Development Bank \\ and \\ Eduardo Levy-Yeyati \\ UTDT, CIPPEC and Brookings Institution
}

Almirante Sáenz Valiente 1010 C1428BIJ Buenos Aires • Tel: (54 11) 5169.7300

Fax: (54 11) 5169.7347 - Web site: http://www.utdt.edu 


\begin{abstract}
$^{*}$
An analysis of the performance of the global financial safety net during the 20082009 crisis, and an evaluation of its new components, indicates that, from an emerging markets perspective, the net remains full of holes despite recent stitches. This paper therefore proposes an effective and workable international lender of last resort (ILLR) for systemic liquidity crises based on: i) an automatic trigger to access the facility; ii) unilateral country prequalification to the facility during Article IV consultations; and iii) liquidity funded by the world's "issuers of last resort." These principles would support a reliable and broad-based ILLR without the carrying costs associated with inefficient reserve hoarding, which would actually work as an effective preventive facility with minimal room for moral hazard.
\end{abstract}

JEL classifications: F33, F34, F42, F53

Keywords: Liquidity Crisis, International Lender of Last Resort, Safety Net

\footnotetext{
${ }^{*}$ The views and interpretations in this document are those of the authors and should not be attributed to the InterAmerican Development Bank. The authors acknowledge comments received by Guillermo Calvo, Steven Kamin, Nicolás Eyzaguirre and participants in the IDB/Brookings conference "Latin America's Economic Future: Prospects and Challenges," participants in the Washington conference of the Reinventing Bretton Woods Committee as well policymakers participating in the meetings of the IDB LAC/G20 Initiative. We are grateful to Jorge Pérez, Tomás Williams and Mariana Barrera for outstanding research assistance.
} 


\section{Introduction}

In the aftermath of the crisis, there seems to be a case for improving the menu of instruments and institutions to protect against global liquidity crunches in a preventive way: multilateral coordination proved that it could respond to the shocks but only belatedly —as a "safety belt" that saves passengers' lives but does not prevent the car crash. Moreover, the recent strengthening of IMF resources and redesigning of instruments, while a move in the right direction, met the demand of only a few countries, and its effectiveness as a protective safety belt remains largely untested. And a new and enhanced menu of facilities offering more complete after-crash protection - which the Fund is actively working on-may still face important political obstacles.

It would be myopic to leave unfinished the pending task of establishing an effective global financial safety net simply because capital flows to emerging markets (EMs) have resumed and liquidity is now plentiful. The hope that the next liquidity crisis in emerging markets will summon the same interest from advanced countries is, in our view, naive, particularly if it does not originate in and involve advanced economies. Now that the memory of the latest crisis is still fresh is the time to move towards reliable preventive arrangements that perform well regardless of the nature of the systemic liquidity crisis. In this piece, we make concrete proposals for a financial safety net to address systemic crises by providing access to a global liquidity facility to countries suffering from exogenous systemic financial shocks, of which the recent global liquidity crunch is a good example. This focus on "liquidity insurance" closely relates to the Global Stabilization Mechanism (GSM) currently under discussion at the IMF. Even within the narrow focus of systemic financial shocks, it is important to recognize that the conditions for activating a global liquidity facility may be not as clear-cut as they were in the recent global crisis. For example, a systemic liquidity crunch due to disruptions in specialized international credit markets may not rise to the level of a global financial disruption, but the systemic financial crisis it would generate among emerging markets could share many of the same characteristics (e.g., the aftermath of the Russian default in the late 1990s). The proposal is not designed to fight yesterday's battle but to generally address systemic liquidity crises affecting developing countries, whether or not they engulf advanced countries.

More broadly, the paper discusses ways to address the financial problems of countries losing fluid access to credit. It approaches the role of the global safety net in providing financial 
assistance as international lending of last resort (ILLR), which covers a wide variety of existing and prospective schemes such as bilateral Central Bank swaps, Central Bank reserves pooling, and various three-letter facilities launched by the IMF in recent years (CCL, RAL, SLF), as well as the recently created Flexible Credit Line or FCL and its offspring, the Precautionary Credit Line or PCL. The recent crisis brought unprecedented advances to ILLR. The discussion assesses the rich experience of the recent crisis and builds on its successful developments. The paper also includes, from a broader perspective, the availability and use of international reserves at the country level as a coping mechanism, irrespective of the importance of a self-protection motivation behind reserve accumulation.

To narrow the scope of the paper, it is useful to distinguish the loss of access to finance resulting from temporary disruptions in the supply of credit (a market problem) from that arising from a perceived deterioration in the country's creditworthiness due to solvency concerns (a country problem). While both are important issues for a global safety net, this paper mainly focuses on the first. It focuses on arrangements designed to address liquidity crises, meaning financial crises resulting from temporary disruptions in global credit markets that can be solved (or substantially alleviated) by the provision of bridge financing to countries. Financial crises prompted by solvency concerns, even if caused by exogenous factors, call for adjustment and/or debt restructuring arrangements that are not analyzed in any detail in this paper.

Nevertheless, it is important to consider the complementary relationship between a global liquidity facility to address liquidity crises and solvency-related arrangements. For example, a global liquidity facility may be unable to successfully solve the systemic financial crisis in all affected countries-whether because the facility is not fully effective in avoiding permanent economic damage or because some countries are also hurt by real shocks that call for corrective policies (e.g., the Greek crisis in 2010)_and it may be necessary to consider the transition to adjustment and restructuring arrangements in a seamless fashion. This paper touches on a few selected aspects relevant to this interaction.

This study also leaves aside traditional country insurance schemes that entail a statecontingent transfer (from the country to the insurer in good times and from the insurer to the country in bad times) $)^{1}$ as opposed to debt-creating "liquidity insurance" that entails lending when

\footnotetext{
${ }^{1}$ Examples include the World Bank’s CCRIF, hedging through derivatives (Caballero and Panageas, 2005), and the use of CAT bonds by sovereigns (as recently in the case of Mexico).
} 
market financial conditions are bad, or in the extreme, lending of last resort. True insurance instruments have not elicited much interest in the present debate because they are difficult to implement both for technical reasons (e.g., illiquid and costly insurance markets) and for political economy reasons, since they entail an up-front cost in exchange for a contingent benefit that may be difficult to sell in the political market. For similar reasons, we leave aside borrowing with insurance-like provisions such as contingent credit lines with private lenders triggered by indicators of liquidity stress, and contractually contingent debt such as automatic haircuts or rescheduling of debt under pre-specified stress conditions. ${ }^{2}$ This paper is about lending, not insurance. As we will see, one key implication of concentrating on ex post lending is that the potential moral hazard created by the safety net can be more easily controlled.

The paper proceeds in three stages. First, we step back to update the debate on the need for an ILLR in an increasingly de-dollarized (but financially globalized) world. In particular, we contrast the experience with alternative varieties of international safety nets, including selfprotection through reserve hoarding, during the recent crisis. Second, we characterize a few key design features of an effective ILLR and propose a blueprint for a global liquidity safety net that articulates and completes the set of existing sources of international liquidity building on current institutions. And third, we revisit with a critical eye existing facilities and proposals, including ongoing revisions to the IMF menu, assess their weaknesses in delivering an effective ILLR, and discuss possible courses of action both within the G20 and at a regional level, where we see a few opportunities for incremental international cooperation concerning enhanced swap arrangements and regional financial arrangements to augment the existing safety net patchwork and supplement continued reliance on self-protection.

\footnotetext{
${ }^{2}$ For a number of reasons (see Broda and Levy-Yeyati, 2002), attempts at private contingent credit lines in Argentina and Mexico in the late 1990s have not been successful in practice. Similarly, the market finds GDPindexed bonds and other exotic arrangements hard to price and punishes them.
} 


\section{New Financial Safety Nets: Do We Need Them?}

An international lender of last resort (ILLR) is prepared to act when no other lender is capable or willing to lend in sufficient volume to deal effectively with financial need to avert a crisis. Calls for an ILLR gained momentum after the financial crises of the late 1990s, when a number of emerging economies suffered financial contagion after the Russian crisis. ${ }^{3}$ In that instance, after the meltdown of key foreign debt-holding institutions that needed to sell assets, those economies faced a sharp deterioration of financial terms and self-fulfilling liquidity runs, a process accelerated by currency mismatches and related balance sheet effects in borrowing countries. The unwillingness of developed countries (and the IMF) to subscribe to the ILLR concept then led emerging economies in Asia and Latin America to embrace a debt dedollarization and self-protection strategy through, respectively, the development of domestic financial markets and the buildup cushion of liquid international reserves-which largely explains why the sharp depreciations in 2008:Q4 and 2009:Q1 did not stress EM financial sectors as they did in the 1990s. In addition, partially as a reaction against the traditional IMF approach, the 2000s witnessed the strengthening of regional safety nets (as in Central Bank agreements such as the Chiang Mai Initiative and the Latin American Reserve Fund).

Given these positive developments, do we still need an ILLR? Those who believe self-protection in the form of international reserves in EMs contributed to the recent global crisis (Allen and Carletti, 2009) would argue in favor of an ILLR in order to reduce reserve accumulation. However, we would argue in favor of the need of an ILLR even if it has little or no effect on reserve accumulation. ${ }^{4}$ The crisis showed that financially globalized economies that benefited from downhill capital movements flows suffered from swings in global risk aversion and liquidity in the form of capital flight and excessive exchange rate volatility, even in the absence of currency imbalances. ${ }^{5}$ In that context, access to foreign currency liquidity proved useful in containing the domestic impact of these external shocks: even in a de-dollarized

\footnotetext{
${ }^{3}$ For example, in 1998 the IDB Washington Conference on World Financial Stability in the wake of the Russian crisis; see proceedings collected in IDB (2000).

${ }^{4}$ A substantial effect would require that aggregate reserve accumulation be driven by precaution. It is difficult to attribute the recent accumulation of reserves in China, Japan and oil-exporting countries (which accounts for the bulk of global imbalances) to a precautionary motive.

${ }^{5}$ Note that, while in the 2000s foreign exposure (typically through unhedged positions in local equity and fixed income markets) no longer entails a substantial currency mismatch as in the past, a capital reversal could still trigger a costly liquidity crunch.
} 
emerging world, an ILLR could still help manage excessively volatile capital flows (on top of the protection afforded by reserves). ${ }^{6}$

At the same time, the recent crisis showed that existing ILLR instruments are not up to the task of global protection. An analysis of the financial havoc in emerging markets resulting from the global financial crisis after the Lehman collapse in September 2008 shows that traditional IMF lending arrangements available at the time did not appear to provide much protection and were in need of revamping. In fact, the impact on risk spreads was widespread across countries irrespective of whether they were covered by existing instruments that could be used to protect them. Under the assumption that only countries not taking part in Article IV consultations (for more than two years) or on the verge of default around the time of the Lehman collapse (as in the case of Ecuador) were not eligible for access to the traditional ILLR arrangements on the books at the time, financial performance after Lehman as measured by the rate of growth in EMBI spreads reveals little difference between access and no-access countries. Based on this comparative measure, the beneficial effect of traditional ILLR was small, or null if the special case of soon-to-default Ecuador is left out of the picture (Figure 1). This evidence justifies the subsequent revamping of ILLR instruments that took place in 2009.

The ineffectiveness of traditional instruments led to the extension of Central Bank swap lines (in our region Mexico and Brazil with the US Fed for USD30 billion each) and the creation of the FCL, a new IMF facility rapidly subscribed to by Colombia, Mexico and Poland. How effective were these new facilities? A cursory look at EMBI spread performance in the beneficiary countries would indicate a significant positive immediate effect at the time of their inception that strengthened over time. However, in order to estimate the effect of these facilities it is important to apply our previous comparative analysis method between eligible and noneligible countries, because a tide of improvement lifted all boats during that period (an average 40 percent compression in EM spreads after the London G20 summit in April 2009 that largely undid the post-Lehman selloff). Since countries with access to these facilities also benefited, their improvement should not be attributed to Central Bank swaps and the FCL. A detailed analysis of performance over time (relative to comparable countries in terms of prior risk

\footnotetext{
${ }^{6}$ The line between liquidity and fundamentals is rather thin: temporary liquidity concerns may quickly evolve into (or reveal pre-existing) fundamental weaknesses. An IILR is needed on both counts.
} 
spreads) ${ }^{7}$ reveals that while the Central Bank swaps exerted a benign (and moderately persistent) influence, the effect of the FCL was more muted and much less persistent (Figure 2). ${ }^{8}$ In that period the undercurrent of improvement was arguably stronger than the benefit of these facilities.

It is nevertheless tempting to attribute the tightening of EM spreads after the London G20 summit in April 2009 to the creation of a new approach in the form of the IMF FCL or the momentum created by the bilateral swaps with the US Fed and the expectation of their widespread application. In this way of thinking, the new facilities offered widespread potential protection and were behind the favorable undercurrent, having therefore a substantial effect beyond the particular countries to which they were applied. However, the new facilities appear too selective to account for the widespread improvement across the country spectrum. In fact, a more rigorous examination of this optimistic interpretation of the evidence also casts serious doubts about it and suggests that the widespread improvement of risk spreads after the London summit cannot be attributed to the availability of these new liquidity facilities. For example, if country potential access to the new facilities is assumed for all countries with prior spreads lower than Colombia (the highest among the explicitly approved countries), the performance of access countries is indistinguishable from that of the rest of the sample (Figure 3). We conclude that an effective global safety net will require improvements in existing ILLR instruments and substantial extension of their country coverage.

\subsection{International Reserves Accumulation and the Self-Protection Motive}

The absence of a reliable ILLR suggests that international reserves may be the safety device of choice. The first question to ask is to what extent is the intense reserve accumulation in recent years motivated by the goal of self-protection? Prima facie, the evidence does not seem to support the precautionary, self-protection motive of reserve accumulation as a primary driver. ${ }^{9}$ The evolution of global international reserve stocks is largely explained by a few countries (China, oil exporters, Japan) with limited liquidity insurance needs (Figure 4). Moreover, even in those countries where capital flow reversals may represent a clear and

\footnotetext{
${ }^{7}$ Using credit ratings as the comparability criteria, while less accurate, yields similar results.

${ }^{8}$ It is somewhat puzzling that the immediate beneficial effect at the time of the FCL request, well documented in Mexico for example, would go away over time in this comparison. An alternative interpretation of the evidence is that the beneficial effect of the FCL was sustained but countries selected for the FCL were in more serious trouble at the time and would have otherwise underperformed relative to the country control group.

${ }^{9}$ For a discussion of the determinants of reserve accumulation, see Levy-Yeyati and Sturzenegger (2010) and references therein.
} 
imminent danger, a casual look at the path of reserve accumulation suggests that the latter is best explained by a leaning-against-the-wind exchange rate policy than by a pure precautionary motive. If reserve accumulation is a by-product of exchange rate smoothing rather than the goal of a self-protection policy (whereby reserves are seen as a liquidity buffer against dollar shortages), it would be unrealistic to expect that an effective ILLR would lead to a significant decline in reserve stocks.

That said, a more nuanced look at the evidence suggests that the prudential motive does play an important but more subtle role. Indeed, in volatile EMs, the two motives are not at odds with each other: one could interpret leaning-against-appreciation policies during expansions as the countercyclical prudential response to procyclical capital flows and real exchange rates. If so, a reliable ILLR may offset the financial incentives to keep current account surpluses as a cushion against capital account reversals. Under this interpretation, traditional analyses would underestimate precautionary reserve levels.

On the other hand, if motivations were entirely related to exchange rate manipulation, the fact that the accumulation of international assets takes the form of lower-yielding liquid reserves (rather than higher-yielding long-run saving instruments, as in the case of sovereign wealth funds) would remain unexplained. This pattern may be simply attributed to traditional reserve management practices and political economy considerations unrelated to exchange rate intervention (e.g., the political cost of marking market losses). ${ }^{10}$ But one could alternatively see in the portfolio choice the reserve managers' self-protection motive: given that intervention is there, it is better to keep the proceeds as a handy liquidity support. If it holds, a successful ILLR may lead Central Banks to extend the duration and risk-return profile of their holdings.

\subsection{International Reserves Stocks and the Self-Protection Option}

Irrespective of the motivations behind reserve accumulation, a large stock of reserves enables countries the option to self-protect under conditions of financial stress. The key question is, therefore, what is needed for a global ILLR to be superior to country reserves and worth the reform effort?

Advocates of the superiority of an ILLR to hoarding national reserves usually highlight three distinct factors: i) lower cost: most indebted emerging economies in need of liquidity

${ }^{10}$ This version of the precautionary story, where the reserve portfolio is the suboptimal outcome of an agency problem, would also go under the radar of existing reserve adequacy analyses. 
insurance need to pay a hefty carrying cost on the order of their sovereign risk premium to hold reserves; ${ }^{11}$ ii) risk pooling and diversification: centralized hoarding by an ILLR will require a smaller stock of low-yielding liquid assets than the aggregation of individual self-protection (or regional reserve pools) for any given level of protection; iii) protection effectiveness: the actual use of international reserves often triggers concerns of a very severe financial stress, producing a perverse signal that renders reserves ineffective as a protection device; and iv) negative externalities: reserves accumulation perpetuates global imbalances and, through their depressing effect on the long risk-free rate, may stimulate asset bubbles.

Concerning the last argument, it exceeds aspects of cost-efficiency from the perspective of individual countries, which is the purpose of this paper. ${ }^{12}$ The other three, however, merit some important qualifications. We think that self-protection through international reserves is a valid strategy and that ILLR would be relatively advantageous only if it is appropriately designed as a supplement to it.

\subsubsection{The Cost of Reserves}

The literature has typically assumed that, to a first approximation, reserves purchases entail issuing public debt for an equal amount. If so, the cost can be estimated as the gap between the marginal cost of hard currency public debt and the return obtained on reserves, in turn estimated as the country risk premium topped by the hard currency term rate premium (as reserves are held in essentially short-dated risk-free assets)—hence the presumably high cost of reserves for risky emerging economies. ${ }^{13}$

However, the costs of reserves are less straightforward than that and may be substantially lower. First, countries usually accelerate reserve accumulation when it is cheap to do so (low risk spreads) and slow the pace or sell reserves when it is expensive (high spreads). This correlation pattern implies that the average spread overestimates the average cost of reserves, especially in periods of high spread volatility. Second, reserve accumulation impacts sovereign spreads; to the extent that liquid reserves often reduce the sovereign spread paid on the total debt stock, the

\footnotetext{
${ }^{11}$ While the liquidity of reserve assets does not require them to be short, Central Banks customarily choose to keep the duration of international reserves rather short, thus adding to carrying cost the interest rate term premium in the reserve currency of choice.

${ }^{12}$ Furthermore, we have expressed above skepticism that liquidity precaution is a main driver of aggregate world reserves, which would be required to expect ILLR to be a significant improvement in this regard.

${ }^{13}$ Albeit sovereign spreads have been declining dramatically for most heavy reserves hoarders, which makes the opportunity cost of holding liquid reserves less taxing.
} 
marginal cost of carrying reserves for indebted economies may be significantly lower than the spread. If, for a given net debt stock, a larger stock of liquid foreign currency assets tightens the sovereign spread, the resulting gain in rollover costs should be netted out from the spread in computing the marginal cost of reserves (Levy-Yeyati, 2008). ${ }^{14}$

Finally, reserves accumulation is typically done by the Central Bank through sterilized interventions (through the sale of local currency-denominated debt), which may result in Central Bank quasi-fiscal losses associated with steep interest rate differentials due to expected local currency depreciation. ${ }^{15}$ However, sterilized intervention of this kind is seldom accompanied by higher interest rates, because appreciation expectations tend to actually depress borrowing costs in the local currency. Instead, to the extent that intervention simply delays the transition to an appreciated exchange rate, it should ultimately lead to a loss in the form of valuation changes (changes in the local currency value of international reserves, i.e., the currency risk of the long dollar position) as the exchange rate appreciates toward the new equilibrium. ${ }^{16}$

Thus, leaning-against-the-wind reserve accumulation would sustain important valuation losses if appreciation pressures are permanent. By contrast, if appreciation turned out to be a transitory phenomenon due, for example, to cyclical inflows or transitory terms of trade shocks, the reversion of the exchange rate to its earlier, more depreciated level would eliminate much of the valuation losses. More generally, in the presence of cyclical fluctuations, a leaning-againstthe-wind Central Bank that allows the exchange rate to follow its fundamental trend over a smoother path is likely to profit from excessive exchange rate volatility.

In theory, expected exchange rate changes built into interest rate differentials between foreign currency reserves and local currency funding would be offset (on average) by valuation

\footnotetext{
${ }^{14}$ There is, of course, a tradeoff between reserves and gross debt concerning their effect on spreads for any given level of net debt; at some point, excessive reserves (and gross debt) may push up spreads as liabilities subject to sovereign risk increase while the benefit of liquidity decreases. From a practical perspective, the fact that both rating agencies and analysts pay increasing attention to measures of the country's net external exposure (e.g., short-term obligations minus current account receipts minus reserves) indicates that reserves are a relevant determinant of the sovereign spread.

${ }^{15}$ See Levy-Yeyati and Sturzenegger (2010). On the other hand, unsterilized (monetized) interventions introduce inflation pressures (and add to expected depreciation). In this case, assuming inflation is fiscally neutral, no direct financial costs are incurred. Inflation, of course, may be economically costly, particularly if it becomes inertial after real exchange rate convergence is achieved. Its opportunity cost is the financial cost of sterilization, which we take as the benchmark cost model.

${ }^{16}$ Note that, under the interest rate parity condition, the difference between the local currency interest rate and the expected appreciation rate should equal the dollar interest rate so that, if expectations are unbiased, the cost of sterilized purchases of reserves should ultimately be, on average, similar to that of purchases directly funded by dollar debt, the only difference being that, in the first case, it is the Central Bank that bears the currency risk.
} 
effects on flows and stocks due to the realized exchange rate changes. Whether that result obtains in practice depends on the accuracy of market expectations. In any case, actual deviations from this average offset may lead to an actual cost of reserves that deviates substantially from the country risk premium benchmark. At any rate, the fact that equilibrium exchange rates are in practice so difficult to assess makes an ex-ante evaluation of long-term intervention costs quite challenging. A quick look at the 2005-2010 rollercoaster illustrates both the leaning-against-thewind nature of exchange rate intervention (reserves were purchased to contain appreciation, and they were sold during currency runs), and the wide cross-country divergence in realized intervention losses (or, in many cases, profits). ${ }^{17}$

\subsubsection{Reserve Pooling, Diversification and the Question of the Reserve Currency}

It has been argued that a centralized or regional reserve pool should reduce the required size of the (costly) liquidity stock due to diversification benefits. This is trivially true in theory, but the diversification gains may be very limited in the event of a systemic crisis. This limitation is even more powerful in the case of a regional pool.

The high correlation risk of the synchronized systemic events for which the ILLR is intended (namely, the fact that all insured countries are likely to draw liquidity at the same time) should largely erode the diversification gains from reserve pooling. The increased co-movement displayed by both the currency selloff and the spread widening after the collapse of Lehman Brothers (Figure 5) is but one piece of evidence among many indicating that the dollar liquidity crunch was experienced by practically every country at the same time. Indeed, as shown by the quick activation of Central Bank swaps within advanced economies, the menu of reserve currencies and assets appeared to be severely restricted mainly to the United States and Japan (and, to a lesser degree, China). A global pool excluding these funding sources, or for that matter a regional pool within Latin America, for example through the Latin American Reserve Fund (LARF, or FLAR in Spanish), would not substantially improve on the status quo of separate country reserves in the case of a systemic event.

\footnotetext{
${ }^{17}$ See Levy-Yeyati (2010a).
} 


\subsubsection{Do Reserves Provide Self-Protection?}

Irrespective of the motivation for accumulation, the key question is whether reserves make a difference in bad times. It is clear from the past crisis that in bad times reserves are actually used to contain exchange market pressures. ${ }^{18}$ Importantly, accumulated reserves can be used at the country's convenience, while borrowing reserves from an ILLR may be subject to uncertainties and unwelcome conditions. All this is prima facie evidence that reserves are relevant to financial policy.

However, views on their effectiveness in counteracting a liquidity crunch are divided because the evidence on impact remains scarce and not clear cut. The mitigating role of reserves in the event of an exogenously driven run on the country's assets has been questioned by a crosscountry comparison of post-Lehman output contractions reported by Blanchard, Faruquee and Das (2010). However, as the authors themselves warn, the complexity of a crisis event in which a financial panic is combined with a global slump makes the identification of the liquidity boost of reserves extremely hard, particularly by looking at low-frequency growth figures that tend to reflect the financial channel only belatedly, if at all.

Indeed, assets prices appear to be a more sensitive gauge of any benign influence of reserves. Any real benefit of a liquidity cushion would lie in its ability to mute capital outflows and exchange rate pressures. Table 1 presents just such an illustration of the way reserves may cushion the impact of global risk aversion on sovereign spreads. Around the time of the Lehman crisis, when liquidity factors played a dominant role, the liquidity position of countries as measured by the Reserves-to-Short Term debt at maturity ratio (comprising short-term debt plus scheduled annual amortizations) was a statistically significant determinant of the rate at which the risk spread widened (the performance measure used in Figures 1 thru 3). If reserves and short-term debt are considered as separate factors, contrary to Blanchard, Faruquee and Das (2010), we find no evidence that short-term debt, rather than reserves, is the factor that drives this result. ${ }^{19}$ While the previous finding does not offer a definitive answer to the question of the effectiveness of reserves as a self-protection tool, it provides some support to the conventional

\footnotetext{
${ }^{18}$ In Latin America, about 5 percent of reserves were used in the first quarter of 2009 alone. Official net lending increased in 2009 by twice that amount, diminishing the pressure to further deplete reserves.

${ }^{19}$ Each one of the two factors appears to make the expected contribution, but due to the small sample size we fail to find a significant statistical effect for any of the two, which we interpret as lack of evidence that reserves fail to protect against the risks posed by short-term debt, as often argued.
} 
view that reserves help contain the run and mitigate the transmission of a financial crisis to the real economy.

Furthermore, even if in some countries the use of reserves failed to be effective, that does not imply that they cannot provide self-protection. If failure resulted from the fact that reserves utilization generates a negative signal revealing serious financial stress to the point of being counterproductive, then the self-protection option would be useless. However, in that case the use of Central Bank swaps also would have failed for the same reason, and it did not. A more plausible interpretation is that if reserves are not sufficiently large for the shock at hand then their use may trigger concerns of sustainability. ${ }^{20}$ By contrast, the availability of a Central Bank swap (and potential extensions) may increase the size of effectively available reserves to a safe level to use. In fact, the very presence of an official credit line should lead to a more aggressive use of reserves and stronger countercyclical fiscal policies because it allays liquidity concerns, presumably increasing the effectiveness of its use (Fernández-Arias and Montiel, 2010). An ILLR would increase the self-protection effectiveness of accumulated reserves even if it does not disburse.

\subsection{Why Do We Need an ILLR?}

If we are willing to accept the premise that reserves accumulation is not a useless and possibly counterproductive prudential policy but rather a valid strategy for protection against systemic liquidity shocks, the question then becomes the following: to what extent and in what dimensions would liquidity provision under the umbrella of the ILLR improve upon self-protection?

Concerning the questions of cost and diversification, a global ILLR would make a material difference only to the extent that it does not need to hoard a liquidity buffer owned and paid for by the beneficiaries. In fact, because the scope for risk diversification is small, the reserves required for such a global safety net would not be materially different from the aggregation of self-protection reserves, nor would the cost of maintaining them in the absence of a third-party guarantee. Can the IMF fill this role? Yes, to the extent that agreements to borrow provide the Fund with free contingent liquidity. This implies that major Central Banks should agree in advance to give access to their balance sheets during a systemic liquidity crunch.

\footnotetext{
${ }^{20}$ Perverse signaling has been argued in Korea to explain the failure to use effectively its US\$ 200 billion reserves relative to using the (potentially very large) US Fed swap line (Baba and Shim, 2010). However, given that shortterm debt obligations were equally large, reserves may have simply looked too small for the task.
} 
An ILLR with access to liquidity on demand would also make a material improvement to protection power relative to reserves-based self-protection. Being limited, reserves may turn out to be insufficient for large shocks. A possible explanation behind the skepticism about the effectiveness of self-protection is that if the size of reserves is not sufficient to allay sustainability concerns, its depletion may itself further stimulate the run. A larger, potentially uncapped ILLR would not encounter this problem, and its mere presence would render reserve use more effective.

Ultimately, in the event of a global liquidity crunch, only the issuer of reserve assets could retain the systemic liquidity risk in good times without a hefty carrying cost-logic that underscores the role played by the US Fed swaps during the crisis. If so, it is not the (arguably minor) diversification margin but the access to liquidity on demand that makes an ILLR more efficient than self-protection from a financial viewpoint and large enough to have an assured effect. ${ }^{21}$

In this light, the critical but often understated question at the core of the global safety net debate is: Are issuers of last resort such as the Fed, the Bank of Japan, or the ECB, or big-pocket lenders such as China willing and able to play this role-or to let a multilateral agent like the IMF do so on their behalf? More precisely: To what extent and under what conditions are these issuers of last resort willing to provide liquidity to the rest of the world when needed?

The recent global crisis originated in advanced countries provided in a sense the most favorable scenario for cooperation, one in which it was in the center's interest to create liquidity and recirculate capital flows fleeing for safety. What would it happen if advanced countries were not engulfed in crisis and the systemic liquidity crisis were felt only in emerging economies (as in the 1990s)? An effective global safety net needs to provide assurances in this regard.

\section{Desirable Features of an Effective ILLR}

Institutions of domestic lending of last resort (LLR) are a good starting point as a model for an ILLR. ${ }^{22}$ LLR takes different forms depending on whether the financial crisis is caused by lack of finance (liquidity crises) or by weak fundamentals (solvency crises). Liquidity crises are

\footnotetext{
${ }^{21}$ It is precisely this aspect, namely, the need of an insurer of last resort to hoard liquidity proportional to the systemic component of the insured event, that makes private insurance against highly correlated events (as in the case of a global liquidity crunch) prohibitively costly. On this, see World Bank (2007).

${ }^{22}$ Fernández-Arias, Gavin and Hausmann (2000) and Cordella and Levy Yeyati (2006a and 2006b) discuss the ILLR role based on the domestic LLR function.
} 
produced by failures on the supply side (e.g., a widespread "run" of investors, a financial shock to the financial system affecting most relevant investing institutions), and therefore can be solved by the temporary provision of liquidity until the market restores normal supply conditions. By contrast, solvency crises require the strengthening of fundamentals and/or debt restructuring in order to regain solvency, an issue this paper leaves aside. ${ }^{23}$

In the case of liquidity crises, the classical principles for LLR can be summarized as follows (based on Bagehot and subsequent authors):

- Lend against any marketable collateral valued at its value in normal times

- Lend in large amounts (on demand) at terms steeper than at market terms in normal times

- Establish the above principles ex-ante and apply them automatically

Notice that penalty terms are applied to ensure that the capital of LLR is not used beyond the period of financial distress; alternatively, in those periods, lending may be restricted to short maturities.

In the international context, the key difference is the question of sovereignty: ILLR is subject to sovereign risk. Sovereigns are not bound by laws enforceable in foreign courts, and collateral is difficult or impossible to post credibly. However, that difference is immaterial provided that ILLR is applied in the presence of adequate financial safeguards; in that case the above principles could be applied, by and large, mutatis mutandis. ${ }^{24}$

Based on the traditional doctrine, we could identify four clearly desirable aspects of a feasible ILLR:

- Large size: Sufficient to meet short-term financial obligations and avoid a collapse (either of demand or supply);

- Expediency: Timely, immediate disbursements to prevent crises rather than cure their consequences or, if already underway, mitigate and resolve them at minimum cost;

\footnotetext{
${ }^{23}$ Fernández-Arias (2010) proposes an integrated ILLR framework to address both as needs arise.

24 There is, moreover, the fact that multilateral lenders have enjoyed so far an implicit preferred creditor status that in practice have ensured that they are repaid even when members defaulted on their private debts.
} 
- Certainty: Automatic (i.e., non-discretionary) financial assistance according to pre-arranged mechanisms and conditions with adequate repayment period to match extraordinary financial need; uncertainty undermines confidence that ILLR will do its job, leads to defensive positioning of stakeholders in anticipation of crisis and, therefore, breeds self-fulfilling crises.

- An exit strategy: Constant monitoring of whether liquidity provision fails to restore normalcy or fundamentals continue to deteriorate in order to be prepared to change diagnosis on the nature of the financial crisis and switch to alternative interventions to strengthen solvency.

There are, in addition, important distinctive characteristics of a feasible ILLR to bear in mind:

- Financial safeguards: In the absence of actual collateral or legal senior creditor status, ILLR financial safety needs a reliable, satisfactory country risk assessment;

- Ex ante eligibility: In the absence of prudential regulation and other legally binding assurances, ILLR needs to resort to the satisfaction of conditions. In order to be expedient and certain, eligibility conditions (including the above risk assessment) ought to be set ex ante, in normal times.

- Standards for eligibility: Conditions for eligibility require minimum standards to comply with the financial safeguards mentioned above and standards of country economic health depending on the objective of the particular application of the ILLR (concerning the soundness of fundamentals, the quality of the policies in place and the degree of commitment to sustain them). In all cases, criteria should be parsimonious, easily quantifiable and as objective as possible. ${ }^{25}$

\footnotetext{
${ }^{25}$ For example, conditions geared towards the country's solvency in order to assess whether liquidity provision is an appropriate remedy may look at indebtedness indicators properly adjusted by exchange rate and other risks, taking into account public and private currency mismatches so as to offset the perverse incentives to borrow in foreign currency introduced by the ILLR's implicit currency guarantee. See Cordella and Levy Yeyati (2006b) and Ostry and Zettelmeyer (2005).
} 
- Participation incentives: Because of the absence of a mandatory legal framework, if countries are reluctant to make individual applications for protection under the ILLR in normal times, the integrity of the safety net will require proactive participation promotion.

An ILLR system would work best when countries arrange their participation in a precautionary mode so that facilities act with speed/certainty and, crucially, agents anticipate such behavior. It is crucial that ILLR has the widest participation possible, so that ILLR protection is known to be in place and is therefore powerful as a preventive instrument. As we argue below, we favor unilateral prequalification as a way to ensure comprehensive participation. In this context, it is important to adopt a no-commitment fee policy to incentivize the preventive use of the facility and to eliminate all barriers to participation. At the same time, these ex ante incentives would be coupled with substantial charges on delivery without prepayment impediments to discourage use of the facility outside of a financial crisis and promote a return to normalcy as soon as possible.

\section{A Blueprint for a Global Liquidity Safety Net}

It may be impossible to devise the perfect liquidity facility a la Bagehot (a window available to solvent countries to obtain up-front temporary foreign currency liquidity assistance at a premium over pre-crisis levels) that is also "incentive compatible"-a facility to which countries can credibly commit some form of collateral and for which all eligible countries are willing to register for payouts in the event of a liquidity shock. This is probably an unrealistic goal, a play that cannot be accomplished with the cards that were dealt.

In a second-best design, however, an ILLR system consistent with our previous discussion is perfectly feasible and could be built on existing institutions if there is political will. We take as a given that the IMF would be the multilateral agency in charge of the ILLR facility. While its central participation would be seen as unhelpful by a number of countries, and there are valid governance and representation concerns, the idea of launching a new multilateral agent independent of the IMF to manage a new liquidity fund looks impractical. Any such institution, to the extent that it relies on the willingness of "reserve countries" to provide liquidity to the rest, will entail less than proportional voting and the same political misgivings that hamper recent IMF facilities. 
The starting point is to utilize the Article IV consultation process to routinely produce unilateral prequalification based on periodic IMF surveillance without any additional condition of approval. This procedure would eliminate the political stigma associated with countries applying for IMF approval that hampered past facilities, thus ensuring broader participation in normal times, for greater preventive effect in the event of a crisis. ${ }^{26}$ In this scheme, the IMF would be in charge of the function of country qualification, including surveillance, review, disqualification and transition to appropriate programs if solvency issues arise. It is critical then that countries disqualified (or denied prequalification) are not unduly hurt, a concern often mentioned. ${ }^{27}$ This function requires technical expertise, equanimity, and political muscle to make tough decisions. Objective qualification criteria are essential on all three counts, limiting arbitrariness and mistrust. Even so, the IMF may be perceived as illegitimate in the absence of checks and balances. Besides limiting its discretion through appropriate objective standards, its legitimacy can be strengthened through collaboration with regional institutions in the process of country prequalification-provided they commit to global standards in dealing with their member countries. ${ }^{28}$

In principle, all countries engaged in constructive Article IV consultations in a position to offer adequate financial safeguards could be qualified for this facility. Conditions concerning adequate macro prudential regulations may also be helpful to ensure that assured access to this facility in the context of domestic regulatory failure does not lead to further exacerbation of private excessive risk-taking within the country.

It is clear that conditioning access to the facility to a determination by the IMF Board or any other body that a legitimate contingency of systemic liquidity crisis is observed would devoid the facility from its preventive power. Access to the facility ought to be triggered automatically, without further approval. Ideally, qualified countries would freely access the facility when they are victims of a systemic liquidity crunch. Following the model of the

\footnotetext{
${ }^{26}$ Naturally, this kind of proactive, unilateral qualification would require the elimination of the commitment fee in order not to bring back the issue of stigma by requiring countries to choose to incur the cost of a commitment fee in good times to be protected in anticipation of problems.

${ }^{27}$ The establishment of a gradual transition for disqualified countries may be important for allaying concerns of becoming members of these facilities and diminish resistance to supporting comprehensive prequalification. Tiered facilities catering to countries' capacities may be effective in supporting ex ante countries disqualified from higher facilities as well as to transition them ex post to more suitable programs if the country's liquidity problems persist or evolve into more permanent solvency problems (Fernández-Arias, 2010).

${ }^{28}$ Even under the status quo based on country initiative, their participation would be helpful in lessening the political stigma of country application.
} 
traditional lender of last resort, lending would take place at penalty rates to discourage the use of the facility in non-emergency circumstances. However, the impediments to credibly pledging valuable collateral to the lender and the absence of a regulator in a position to block the opportunistic use of the facility opens this model to additional risks in the international context and may prevent consensus on implementation of broad country coverage.

As the proposed facility is designed for a systemic liquidity shock, an attractive solution to this tradeoff between certainty of access and broad eligibility (i.e., between restrictiveness and inclusiveness) would be to preserve automatic access for a selected group of countries with the highest qualifications (say those reaching FCL standards) or able to pledge acceptable international collateral (say illiquid sovereign wealth funds) but make it contingent on the objective verification of the covered contingency (the global shock) for a broader group. For example, once a stipulated and objectively verifiable sudden and widespread deterioration of financial indicators is observed, qualified countries would have the full right to access the facility at will. The very nature of the case at hand strongly points to a presumption that countries hit will remain solvent if liquidity is provided, and therefore qualification standards ought to be minimal in order to encompass the typical country in liquidity crisis. ${ }^{29}$

The concern that such extension of automatic support in bad times would not be workable because of moral hazard is misguided. Moral hazard arises when a party is able to steer resources in its favor by taking certain (inefficient) actions. True insurance to cover the risk of lack of liquidity could be the source of moral hazard if the triggering event for the insurance payout (e.g., a sizable increase in the country's spread) or the amount to be covered by the payout (e.g., the shortfall relative to a safe Reserves-to-Short term debt ratio) can be affected by countries' opportunistic actions, as in the examples. Even if the insurance is fair and premiums are collected in the expectation of such actions, such an insurance system would evidently lead to inefficient behavior which ought to be controlled for the good of the country. However, the ILLR arrangements discussed in this paper are not insurance but (contingent) lending. To the extent that lending is paid back (at the lender's funding rate), there is no scope for countries to take advantage through inefficient opportunistic actions and therefore no country moral hazard. In

\footnotetext{
${ }^{29}$ Fernández-Arias (2010) proposes a liquidity facility triggered by a widespread increase in EMBI spreads beyond an agreed-upon threshold available to all countries under regular Article IV review, barring extreme cases of country solvency risk..
} 
other words, the country would internalize the effects of all its actions: any inefficient action taken would not result in higher transfers in its favor, only in lower welfare. ${ }^{30}$

This is also true for an investors' "bailout” provided that the country agreeing to such arrangement, instead of incurring the costs of debt restructuring, pays back the ILLR financing the bailout. As long as lending is done against sufficient financial safeguards of repayment, as proposed, there is no room for country moral hazard. This case is especially strong in the context of a systemic liquidity facility because, as the triggering event is an exogenous liquidity shock, there is the strong presumption that no fundamental problem interfering with the capacity to repay will develop as long as liquidity is provided. Sometimes the argument is made that a liberal liquidity facility would lead to countries taking riskier decisions, but that is precisely the point of a safety net. For example, countries may hoard a lower amount of precautionary reserves. The safety net (offered at the lenders' funding cost) does not reward irresponsible risky behavior but eliminates the unnecessary risk of liquidity collapses.

Conditionalities beyond those pertaining to financial safeguards attached to liquidity provision in a liquidity crisis would be, in principle, similarly misguided. ${ }^{31}$ As mentioned, since there is no scope for country moral hazard, there is also no justifiable conditionality to control its inefficient manifestations. To the extent that a safety net is very valuable to a country in a liquidity crisis, an ILLR could presumably extract extraneous conditionality agreements in return, but that could not be justified as a device to control for moral hazard. ${ }^{32}$

There is, however, a case for concern if the country's macro prudential regulations are inadequate, because in that case the elimination of the systemic liquidity risk may have the unintended consequence of exacerbating already excessive private risk-taking. This problem does not originate in the ILLR, and its solution resides in domestic regulatory reform. Nevertheless, some ILLR eligibility conditions connected to relevant financial prudential regulation may be considered to the extent that they provide reasonably effective ex ante

\footnotetext{
${ }^{30}$ This assumes no negative international spillovers transferring costs to third parties, which does not appear to be a material consideration in this case.

${ }^{31}$ The exception would be conditions concerning international cooperation. While moral hazard is moot because countries in principle internalize the effects of their actions, international spillovers of interest to the safety net would not.

${ }^{32}$ Moreover, by preventing avoidable and costly liquidity crises that may derail reforms with backloaded payoffs, a safety net could lengthen the horizon of the policymaker, promoting sustainable policies (Cordella and Levy Yeyati, 2006b). However, if solvency considerations are relevant, then both moral hazard and conditionality require a more nuanced discussion; concerning liquidity facilities, the risk of country moral hazard resides in misdiagnosing solvency crises as liquidity crises (Fernández-Arias, 1996).
} 
incentives for needed reform in domestic regulation that may outweigh the lost ex post benefit of liquidity cover for countries which would not reform. Importantly, this consideration of secondbest policy is not specific to ILLR, as it applies equally to domestic lending of last resort. If the regulatory framework is good enough to justify a domestic lender of last resort, it should be also good enough for the ILLR we envisage (as long as the country's repayment is not in jeopardy).

As mentioned, there is a responsibility of reserve asset countries to give access to the ILLR to liquidity on demand. The source of liquidity is a network of Central Bank swaps and other reliable sources of liquidity, including regional arrangements in a position to cofinance, committed to fulfill their obligations once it is certified that the qualified countries are entitled to the facility.

On the basis that there exists an appropriate funding source of contingent liquidity, there is the function of channeling liquidity to qualified countries, which can be separated from the function of country qualification mentioned above. How this liquidity is intermediated is open to variations. One simple alternative is to let the qualifying institution (the IMF) also be the institution channeling funds to its member countries according to its standard lending practices. This implies that the IMF would in turn be entitled to borrow from funding sources. Another alternative is for the IMF to coordinate lending off its balance sheet, so that the funding source enters into financial transactions with qualified members (always with the obligation to serve them all). Yet another alternative is to allow regional institutions, for example the LARF in Latin America, to channel the resources to its regional member countries that are qualified. The regional institution may be the beneficiary of IMF lending, acting in this way as an intermediary of the IMF, or deal directly with the funding source under the supervision of the IMF. ${ }^{33}$

\section{A Quick Look at the IMF Menu}

What progress is being made? Possibly in light of the only partial success of the FCL, there are a number of avenues currently being explored (or about to be launched) by the IMF to enhance their menu of liquidity facilities. These include, most notably, enhancements to the FCL to

\footnotetext{
${ }^{33}$ The issuance of unconvertible SDR by the IMF represents an inversion of the problem: The IMF "issues" on behalf of the issuers of last resort (which commit to monetizing SDRs by making them convertible into reserve currencies), without deciding on the allocation (based on the IMF quota distribution). Going back to the LLR analogy, SDR issuance would be similar to an injection of liquidity through open market operations that leave the allocation to the market, as opposed to a targeted assistance to the institutions facing the liquidity shortage.
} 
achieve two objectives: i) make it available, under less generous conditions, to members that are not eligible under the current ex ante conditionality; and ii) make it more attractive to already eligible or potentially eligible but indifferent members.

Regarding the first objective, the IMF launched a Precautionary Credit Line (PCL) subject to lower requirements than the FCL but with ex post conditions on performance, albeit lighter than HAPA's (with a six-month monitoring frequency and 10-quota lending limit, or 5quota upon approval). Essentially, this new facility lies halfway between a HAPA (itself a streamlined SBA) and the original FCL. While it may simplify access for program countries, it does not introduce anything qualitatively new to the menu or the way country qualification is processed. In fact, the multiplication of tiers without clear and verifiable eligibility standards may add to countries' apprehension to participate. In any event, wide country protection against systemic liquidity crises remains an issue to be tackled, perhaps under the rubric of Global Stabilization Mechanism or GSM (to be discussed further below).

Regarding the second objective, the exit problem was smoothed out through the lengthening of the FCL eligibility period (FCL arrangements can now be approved for one year, or two years with an interim review after one year) and the lending cap was removed (access levels are to be assigned on a country-by-country basis, presumably ex ante). While these marginal changes respond to countries' demands, in order to evaluate the reforms announced or proposed, it is useful to start by asking why so many of the potentially FCL-eligible countries ignore the new facility. While many of the possible answers go back to the ones behind the failure of the FCL's predecessors (the CCL and the RAL), the experience with the FCL, which after all did have three takers, provided some new information. Now that fears of being punished by the market have been put to rest (as noted above, the market response to the FCL request by Mexico, Poland and Colombia was positive), it became clear that, if there is a stigma associated with IMF involvement, its roots are political rather than economic. On that front, the need for a formal request that needs to be approved by the IMF Board now looks more than ever like a potentially crucial obstacle.

While unilateral prequalification could go a long way towards increasing the influence of the FCL, this facility cannot be the seed of the ILLR in a global safety net. While it is true that participating countries would be able to access on demand substantial amounts without conditionality, FCL country eligibility conditions are very stringent, and therefore the facility is 
very selective. It is difficult to think that eligibility conditions for a facility granting extremely liberal access to up-front borrowing under any kind of financial shock a country may suffer can be relaxed to the point of widespread country participation. The FCL is selective by design. Widespread participation granting this kind of access requires limiting the facility to liquidity crises, and more to the point of this paper, systemic liquidity crises. This kind of financial crisis does provide the presumption of solvency required to grant liberal access to liquidity. Our facility blueprint is specifically designed for this purpose.

Some of the more ambitious innovations are still proposals waiting for IMF Board consideration, under a new encompassing name: the Global Stabilization Mechanism (GSM). ${ }^{34}$ The GSM, which in principle would be activated at the onset of a global crisis, introduces two important additions. First, the option to unilaterally grant access to the FCL for "systemic"countries - a hint at a facility that mimics (and possibl, takes over) the role of the Fed swap or, more generally, the automaticity of access discussed in the previous section. If so, the GSM would solve the entry problem that plagued past incarnations of IMF liquidity facilities for these systemic cases. Judging from the recently published IMF list of 25 countries of financial systemic importance, systemic countries in Latin America would include Brazil and Mexico.

Also, the GSM would manage a new liquidity window (the Short-Term Liquidity Line, or SLL) without ex post conditionality, which would be available to PCL-eligible countries during episodes of global distress - in other words, extending an FCL-type of assistance to PCLeligible countries. Thus, one could assume, the IMF is gradually pushing the line to make many financially large FCL countries automatically eligible (that is, without the need for a formal request), and to make many formerly "program" countries FCL eligible on exceptional occasions. Last but not least, the GSM sees the IMF at the center of a multipolar liquidity safety network, coordinating the response to a global crisis with monetary authorities and regional arrangements, as well as with the private sector, deciding on SDR allocations, and overseeing all other IMF facilities (including expedient and frontloaded programs).

Overall, the GSM probably reflects the current frontier where the internal policy discussion and the external member demand for reform can bring IMF facilities, and this would

\footnotetext{
${ }^{34}$ See International Monetary Fund (2010).
} 
be a positive development. Nevertheless, from the perspective of emerging economies, the proposal as outlined has some drawbacks.

What's missing from the menu? The first drawback is, of course, that access would be subject to Board approval: everything suggests that the IMF Board would oppose the muchneeded automatic access on grounds of moral hazard concerns (discussed in the previous section) and favor approval on a case-by-case basis, with the possible exception of a few "systemic" cases already blessed by the US Fed in the last crisis. ${ }^{35}$ In the latter case, replacing the Fed swap by the automatic FCL for the same set of countries can hardly be seen as an improvement (and it may well be regarded as a step back by the countries involved). A second shortcoming of the new package is its potential lack of predictability: if the activation of the GSM and all its features (automatic access to liquidity, or conditional access to the SLL) depends on the subjective IMF definition of a global crisis and its timely verification, in normal times the new mechanism will likely have little if any effect in terms of prevention, self-protection and risk pricing by the market. A third deficit of the new proposal lies in the fact that, despite all its good intentions, the objective of fostering demand for IMF facilities by solvent emerging markets under liquidity stress is only partially addressed, since from the entry perspective only selected "non-systemic" economies may see some protection improvement, far short of the widespread participation facility that a systemic liquidity shock calls for. ${ }^{36}$ Irrespective of its global protection rationality, discrimination in favor of "systemic" countries is not helpful in fostering participation.

With the caveat that available information about the ongoing IMF reform is only preliminary, one thing stands out on the liability side: most non-systemic emerging economies (including many G20 members) will be left outside of the automatic (unilateral) qualification slot of the GSM. Moreover, the spontaneous extension of Central Bank swap arrangements (particularly, the Fed's) to selected emerging economies is bound to be made redundant by some features of the GSM, which ultimately may represent a step away from tried and proven Central

\footnotetext{
${ }^{35}$ There is, in addition, the resource problem: the GSM, with its enhanced access and automatic liquidity to large countries, involves more generous lending commitments and, if successful in eliciting the Board's interest, will require important additions to the IMF resource pool.

${ }^{36}$ On the positive side, note that the idea of selectively dropping ex post conditionality in periods of global distress is in line with the criterion of broadening automatic access during crisis that we propose in the previous section, to deal with the tradeoff between restrictiveness and inclusiveness implicit in the facility.
} 
Bank swap lines without significantly extending their scope. In fact, if anything, our analysis shows that these swaps were more effective than the FCL support that would replace them.

Will the new IMF approach, coupled with the proposed quota reform, be enough to bypass political concerns behind the lack of interest in the past? Can it grow into a liquidity facility with an automatic trigger and widespread prequalification? It appears that the latest IMF batch will set the limit on how far the institution can move towards a true ILLR in the near future, along the lines of our blueprint. ${ }^{37}$ If approved, it will represent important progress in the right direction that enhances access to selected "program" countries eligible for the PCL but, as we noted above, probably less than enough for typical advanced emerging economies seeking to cushion external liquidity shocks or fledgling developing countries still integrating into global financial markets.

\section{Concluding Remarks: Where Do We Go From Here?}

We need to hope for the best but plan for the worst. The best in our view would be an ILLR along the lines of our blueprint. However, if despite the unprecedented momentum towards ILLR activity reform fatigue sets in, as it often happens after liquidity problems hide out of sight in the economic cycle, we need to consider alternatives to global ILLR reform. Given the previous discussion, one way to go could to establish an ILLR system that would rely less on IMF intervention. ILLR could be thought as a multilateral network of Central Bank swaps, possibly under the technical management of the IMF: a more explicit (and predictable) version of what the Fund has been doing for years, namely, leveraging on the issuers of reserve currencies to fund its assistance programs. ${ }^{38}$ One could conceive of the multilateral manager as a facilitator: an independent entity that manages existing and enhanced Central Bank swap agreements in one big liquidity network for eligible countries, and stands ready to pass the baton (or, in the case of the IMF, step in) with traditional programs should liquidity fail to cure the patient. A multilateral swap network based on ex ante verifiable eligibility conditions of the type indicated in Section 3 may involve only minimal participation of the IMF (little more than a technical unit, much in the same way intended for the Framework exercise within the G20

\footnotetext{
${ }^{37}$ The G20 seem to have acknowledged that. In its recent Seoul Communiqué, the group salutes the enhancement of the FCL, the creation of the PCL, and the intention of the IMF to further improve its capacity to cope with systemic shocks and to enhance collaboration with Regional Financing Arrangements (RFAs), both included in the GSM currently under debate. Thus, the G20 GFSN working group appears to have given up on a facility of its own design. 38 See Cordella and Levy Yeyati (2010).
} 
meetings), thus mitigating any distrust that IMF Board decisions may generate. Complete specification of objective qualification criteria may not be the best technical approach to standards but may be the necessary price to pay for a working system with ample coverage if our IMF-centered blueprint cannot be implemented.

What would be the advantage of a multilateral network over existing bilateral arrangements? If well designed, the multilateral version would mitigate the drawbacks detected in the design of the bilateral schemes: it would be generous, free of political interference, available to a broader group of countries on a more predictable basis (along the lines discussed in Section 3), and with a clear procedure to exit to an adjustment program if needed. Existing bilateral arrangements created in the heat of the moment of the last crisis may be easily folded back and forgotten once recovery takes hold. A multilateral network has a better chance of becoming an established institution available for the next systemic crisis. A multilateral network would also more easily insert regional arrangements as intermediaries, which would elicit fewer political misgivings.

In this connection, the design and experience of the Chiang Mai Initiative (CM) may offer a useful perspective to assess the possibilities of multilateral Central Bank networks and the role of the IMF in them. ${ }^{39}$ As a reaction to the negative experience with IMF liquidity support in the 1997/98 Asian financial crisis, Asian leaders met in Chiang Mai and agreed on expanding a network of small swap facilities within the ASEAN group (relatively weak countries) and on bilateral swap arrangements between ASEAN countries with Korea, China and Japan (strong countries committing to swap US dollars). This second set of arrangements was tightly capped unless the country accepted to have a program with the IMF, the so-called IMF link, as a way to introduce discipline into the agreement. CM was not used in the recent crisis despite clear need in some of the countries; Korea, for example, chose to arrange a swap with the US Fed instead. Arguably, the IMF link was the key deterrent to using CM. The system is now being replaced after the recent crisis by a reserves pool system (of US\$ 120 billion) against which the weak countries would be able to borrow a multiple of their contribution (the CM multilateralization) subject to IMF agreement (Table 2). In this pooling arrangement, the three strong countries contribute the lion's share of the pool and have token borrowing rights (a fraction of their contribution).

\footnotetext{
${ }^{39}$ See Sussangkam (2010)
} 
Arrangements like CM's cannot be replicated in Latin America because it lacks the strong countries. ${ }^{40}$ Other than that, the new CM pool arrangement that is emerging is similar in nature to LARF's except that CM retains the IMF link. Another important difference is that LARF is highly leveraged in the sense that aggregate borrowing rights far exceed aggregate contributions to the pool while CM is not, which implies that LARF's borrowing rights shown in Table 2 could not be fulfilled in the case of a systemic crisis. By contrast, CM is able to provide high (effective) borrowing rights to the weaker countries even in this case of ample demand because the strong countries are net contributors. To emulate this model, the LARF ought to incorporate Brazil and, especially, strong countries in the Western Hemisphere such as Canada and, of course, the United States. ${ }^{41}$ While borrowing rights in CM not subject to IMF agreement are not larger than LARF's, the question of the IMF link may come to the fore if the LARF pool becomes larger in size and membership.

In sum, we hope for the implementation of a global safety net for systemic liquidity crises in which: i) the IMF prequalifies countries to the facility in connection with Article IV consultations on the basis of minimal standards of financial safeguards and, possibly, domestic macro prudential regulation; ii) there is automatic access to the facility without the need for a subjective Board determination; and iii) the facility is well funded by reserve currency issuers and asset holders with a free credit line for this purpose. We offer some ideas for making progress towards a multilateral network of Central Bank swaps along these lines.

Short of this global solution, each of the existing liquidity assistance alternatives (old and new IMF facilities, regional financial institutions, Central Bank swaps) should usefully complement each other to offer equitable access to liquidity to solvent countries under stress in a more foreseeable way. Own reserves would likely continue to be a first line of defense for those countries that have a sizeable stock, but they could be made more effective as part of a larger regional and global network of back-up liquidity sources.

\footnotetext{
${ }^{40}$ The European region also has a strong anchor in Germany, which allows it to recreate a regional IMF if it so chooses.

${ }^{41}$ Alternatively, perhaps advanced countries would more naturally associate with a regional power, say Brazil, to in turn supervise liquidity provision within the LAC region.
} 


\section{References}

Allen, F., and E. Carletti. 2009. “The Global Financial Crisis.” Paper presented at the 13th Annual Conference of the Central Bank of Chile. Available at: http://www.bcentral.cl/eng/conferences-seminars/annual-conferences/2009/Program.htm.

Baba, N., and I. Shim. 2010. "Policy Response to Dislocations in the FX Swap Market: The Experience of Korea.” BIS Quarterly Review June 2010: 29-39. Available at: http://www.bis.org/publ/qtrpdf/r_qt1006e.pdf

Blanchard, O., H. Faruqee and M. Das. 2010. "The Initial Impact of the Crisis on Emerging Market Countries.” Brookings Papers on Economic Activity Spring 2010: 263-307. Broda, C., and E. Levy-Yeyati. 2002. "Dollarization and the Lender of Last Resort.” In: E. Levy-Yeyati and F. Sturzenegger, editors. Dollarization. Cambridge, United States: MIT Press.

Caballero, R., and S. Panageas. 2005. “A Quantitative Model of Sudden Stops and External Liquidity Management.” NBER Working Paper 11293. Cambridge, United States: National Bureau of Economic Research.

Cordella, T., and E. Levy-Yeyati. 2006a. “The IMF as Country Insurer.” In: E. Truman, editor. Reforming the IMF for the 21st Century. Washington, DC, United States: Peterson Institute for International Economics.

----. 2006b. “A (New) Country Insurance Facility.” International Finance 9(1): 1-36.

----. 2010. “Global Safety Nets: The IMF as a Swap Clearing House.” http://www.voxeu.org/index.php?q=node/4899.

Fernández-Arias, E. 1996. “Balance-of-Payments Rescue Packages: Can They Work?” Research Department Working Paper 333. Washington, DC, United States: Inter-American Development Bank.

http://www.iadb.org/research/pub_desc.cfm?language=English\&PUB_ID=WP-333.

----. 2010. “International Lending of Last Resort and Sovereign Debt Restructuring.” In: C. Primo and G. Vincellete, editors. Sovereign Debt and the Financial Crisis: Will This Time Be Different? Washington, DC, United States: World Bank.

Fernández-Arias, E., M. Gavin and R. Hausmann. 2000. "Preventing Crisis and Contagion: The Role of International Financial Institutions.” In: E. Fernández-Arias and R. Hausmann, 
editors. Wanted: World Financial Stability. Baltimore, United States: Johns Hopkins University Press.

Fernández-Arias, E., and P. Montiel. 2010. “The Great Recession, 'Rainy Day' Funds, and Countercyclical Fiscal Policy in Latin America.” Forthcoming in Contemporary Economic Policy.

Inter-American Development Bank (IDB). 2000. Wanted: World Financial Stability. E. Fernández-Arias and R. Hausmann, editors. Baltimore, United States: Johns Hopkins University Press.

----. 2010. The Aftermath of the Crisis: Policy Lessons and Challenges Ahead for Latin America and the Caribbean. A. Izquierdo and E. Talvi, coordinators. Washington, DC, United States: IDB.

International Monetary Fund (IMF). 2010. “The Fund’s Mandate-The Future Financing Role: Reform Proposals.” Washington, DC, United States: International Monetary Fund.

Available at: http://www.imf.org/external/np/pp/eng/2010/062910.pdf

Kenen, P. 2007. “IMF Reform: A Marathon, Not a Sprint.” Available at: http://www.voxeu.org/index.php?q=node/680.

Lane, P., and G. Milesi-Ferretti. 2009. "Where Did All the Borrowing Go? A Forensic Analysis of the U.S. External Position.” Journal of the Japanese and International Economies 23(2): 177-199.

Levy Yeyati, E. 2008. “The Cost of Reserves.” Economic Letters 100(1): 39-42.

----. 2010a. "What Drives Reserve Accumulation (and at What Cost)?” http://www.voxeu.org/index.php?q=node/5579.

----. 2010b. “The G20 Agenda from a Latin American Perspective: A Primer.” Washington, DC, United States: Inter-American Development Bank. Mimeographed document.

Levy-Yeyati, E., and F. Sturzenegger. 2010. “Monetary and Exchange Rate Policies.” In: D. Rodrik and M. Rosenzweig, editors. Handbook of Development Economics Vol. 5: The Economics of Development Policy. Amsterdam, The Netherlands: Elsevier.

Mateos, I., R. Duttagupta and R. Goyal. 2009. “The Debate on the International Monetary System.” IMF Staff Position Note, SPN/09/26. Washington, DC, United States: International Monetary Fund. http://www.imf.org/external/pubs/ft/spn/2009/spn0926.pdf 
Obstfeld, M., J. Shambaugh and A. Taylor. 2009. "Financial Instability, Reserves, and Central Bank Swap Lines in the Panic of 2008.” American Economic Review 99(2): 480-486.

Ostry, J., and J. Zettelmeyer. 2005. “Strengthening IMF Crisis Prevention.” IMF Working Paper 05/206. Washington, DC, United States: International Monetary Fund.

Sussangkam, C. 2010. “The Chiang Mai Initiative Multilateralization: Origin, Development and Outlook.” ADB Working Paper 230. Manila, The Philippines: Asian Development Bank.

World Bank. 2007. Country Insurance: Reducing Systemic Vulnerabilities in LAC. Washington, DC, United States: World Bank. 
Table 1. The Benign Effect of Reserves on Spreads

\begin{tabular}{|c|c|c|c|c}
\multicolumn{5}{c}{ Dependent variable: Spread Growth } \\
\hline Reserves/GDP & & $\begin{array}{c}-0.0489 \\
(0.0489)\end{array}$ & $\begin{array}{c}-0.0220 \\
(0.0470)\end{array}$ & \\
Short term & & 0.109 & & 0.0804 \\
debt/GDP & & $(0.0659)$ & & $(0.0606)$ \\
& & & & \\
Reserves/Debt & $-0.0856^{* *}$ & & & \\
& $(0.0416)$ & & & \\
Constant & $1.082^{* * *}$ & $1.157 * * *$ & $0.942^{* * *}$ & $0.942^{* * *}$ \\
& $(0.0657)$ & $(0.163)$ & $(0.0928)$ & $(0.0928)$ \\
Observations & 32 & 32 & 33 & 33 \\
R-squared & 0.124 & 0.093 & 0.007 & 0.007 \\
\end{tabular}

Standard errors in parentheses. All variables in logs.

*** $\mathrm{p}<0.01,{ }^{* *} \mathrm{p}<0.05,{ }^{*} \mathrm{p}<0.1$ 
Table 2. Comparison of Borrowing Quotas

\begin{tabular}{|c|c|c|c|c|c|c|}
\hline \multicolumn{7}{|c|}{ Chiang Mai Initiative Multilateralized } \\
\hline Country & Contribution & Multiplier & $\begin{array}{c}\text { Borrowing } \\
\text { Quota }\end{array}$ & $\begin{array}{c}\text { Borrowing } \\
\text { Quota (\% } \\
\text { GDP) }\end{array}$ & $\begin{array}{c}\text { IMF } \\
\text { Delinked } \\
\text { Borrowing } \\
\text { Quota }\end{array}$ & $\begin{array}{c}\text { IMF } \\
\text { Delinked } \\
\text { Borrowing } \\
\text { Quota (\% } \\
\text { GDP) }\end{array}$ \\
\hline Brunei & 0.01 & 5.00 & 0.05 & $0.38 \%$ & 0.01 & $0.08 \%$ \\
\hline Cambodia & 0.12 & 5.00 & 0.60 & $5.75 \%$ & 0.12 & $1.15 \%$ \\
\hline China - Mainland & 34.20 & 0.50 & 17.10 & $0.35 \%$ & 3.42 & $0.07 \%$ \\
\hline China - Hong Kong* & 4.20 & 2.50 & 10.50 & $4.99 \%$ & 2.10 & $1.00 \%$ \\
\hline Indonesia & 4.77 & 2.50 & 11.93 & $2.21 \%$ & 2.39 & $0.44 \%$ \\
\hline Japan & 38.40 & 0.50 & 19.20 & $0.38 \%$ & 3.84 & $0.08 \%$ \\
\hline Korea & 19.20 & 1.00 & 19.20 & $2.31 \%$ & 3.84 & $0.46 \%$ \\
\hline Lao PDR & 0.03 & 5.00 & 0.15 & $2.66 \%$ & 0.03 & $0.53 \%$ \\
\hline Malaysia & 4.77 & 2.50 & 11.93 & $6.18 \%$ & 2.39 & $1.24 \%$ \\
\hline Myanmar & 0.06 & 5.00 & 0.30 & $1.14 \%$ & 0.06 & $0.23 \%$ \\
\hline Philippines & 3.68 & 2.50 & 9.20 & $5.71 \%$ & 1.84 & $1.14 \%$ \\
\hline Singapore & 4.77 & 2.50 & 11.93 & $6.54 \%$ & 2.39 & $1.31 \%$ \\
\hline Thailand & 4.77 & 2.50 & 11.93 & $4.52 \%$ & 2.39 & $0.90 \%$ \\
\hline Vietnam & 1.00 & 5.00 & 5.00 & $5.37 \%$ & 1.00 & $1.07 \%$ \\
\hline \multicolumn{7}{|l|}{ Total } \\
\hline Contributions & \multicolumn{2}{|l|}{119.98} & Average & $3.46 \%$ & & $0.69 \%$ \\
\hline Total Borrowing & \multicolumn{2}{|l|}{129} & & & & \\
\hline $\begin{array}{l}\text { Ratio to } \\
\text { contributions }\end{array}$ & 1.08 & & & & & \\
\hline
\end{tabular}


Table 2., continued

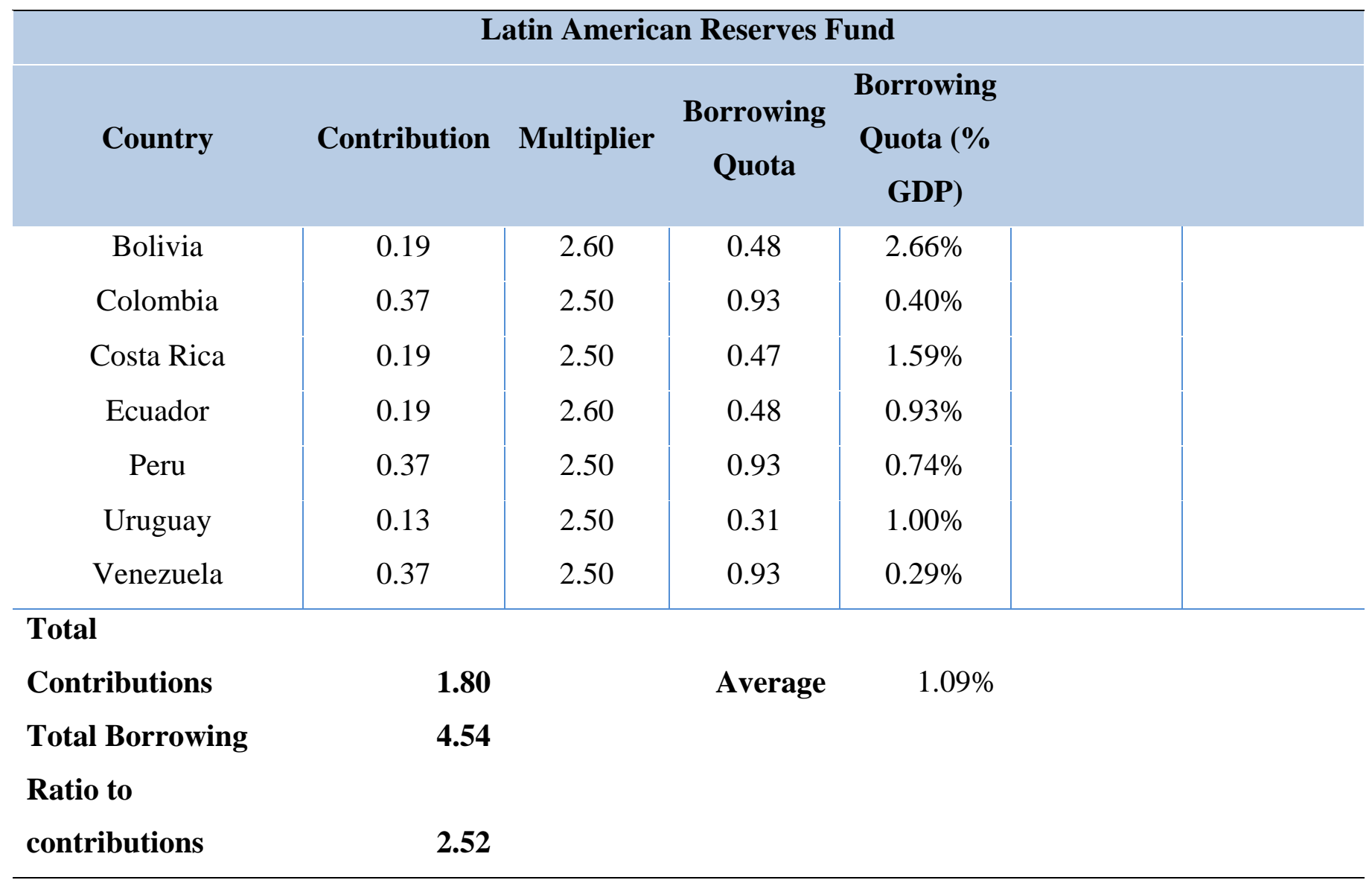

Note: Unit of measurement is US\$ billion.

Sources: Sussangkarn (2010), Economist Intelligence Unit and authors' calculations.

* Hong Kong, China’s borrowing is limited to IMF delinked portion because Hong Kong, China is not a member of the IMF. 
Figure 1: Effect of access to credit facilities on EMBI Spreads

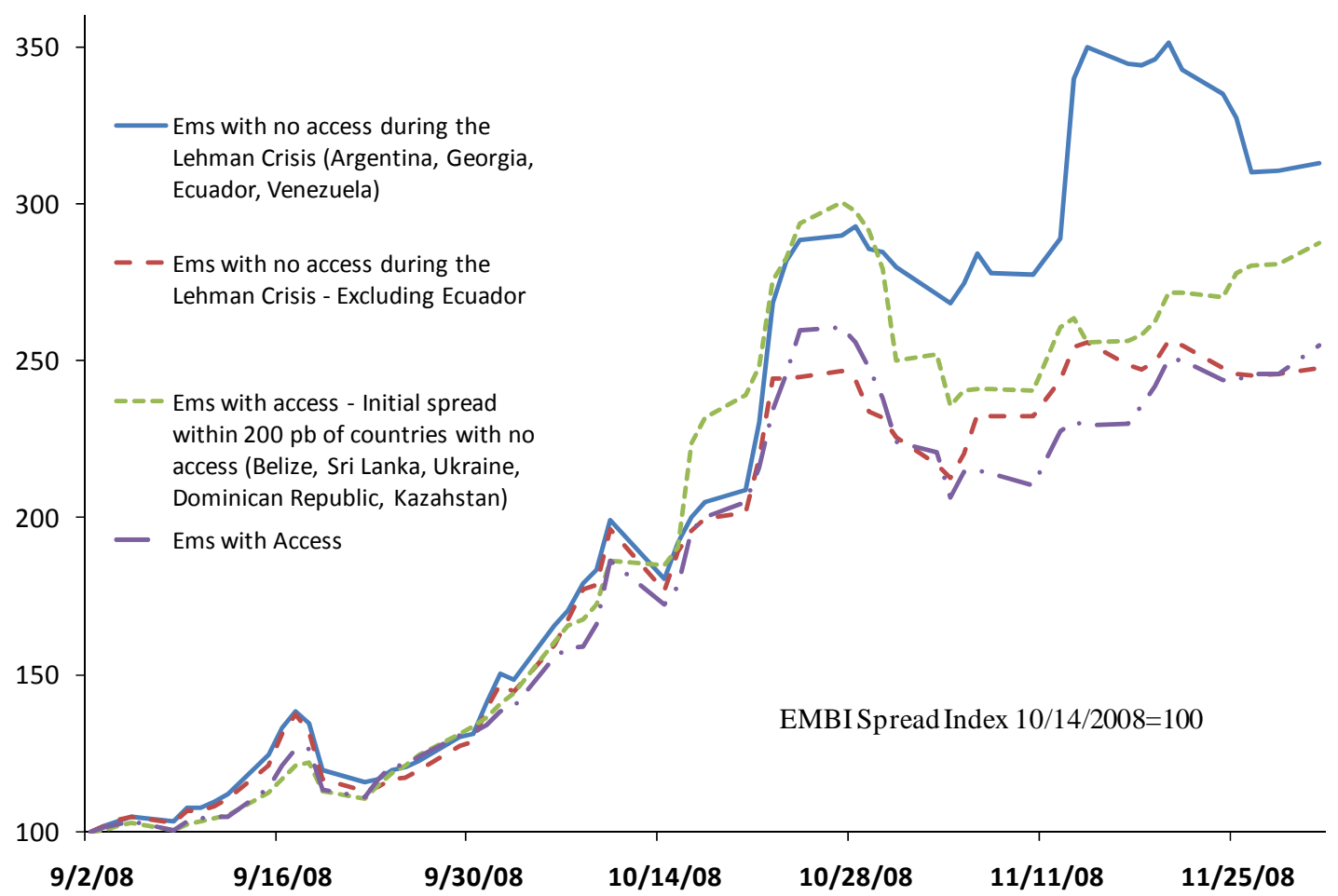

Figure 2: Effects of Fed Swaps and FCL on EMBI Spreads

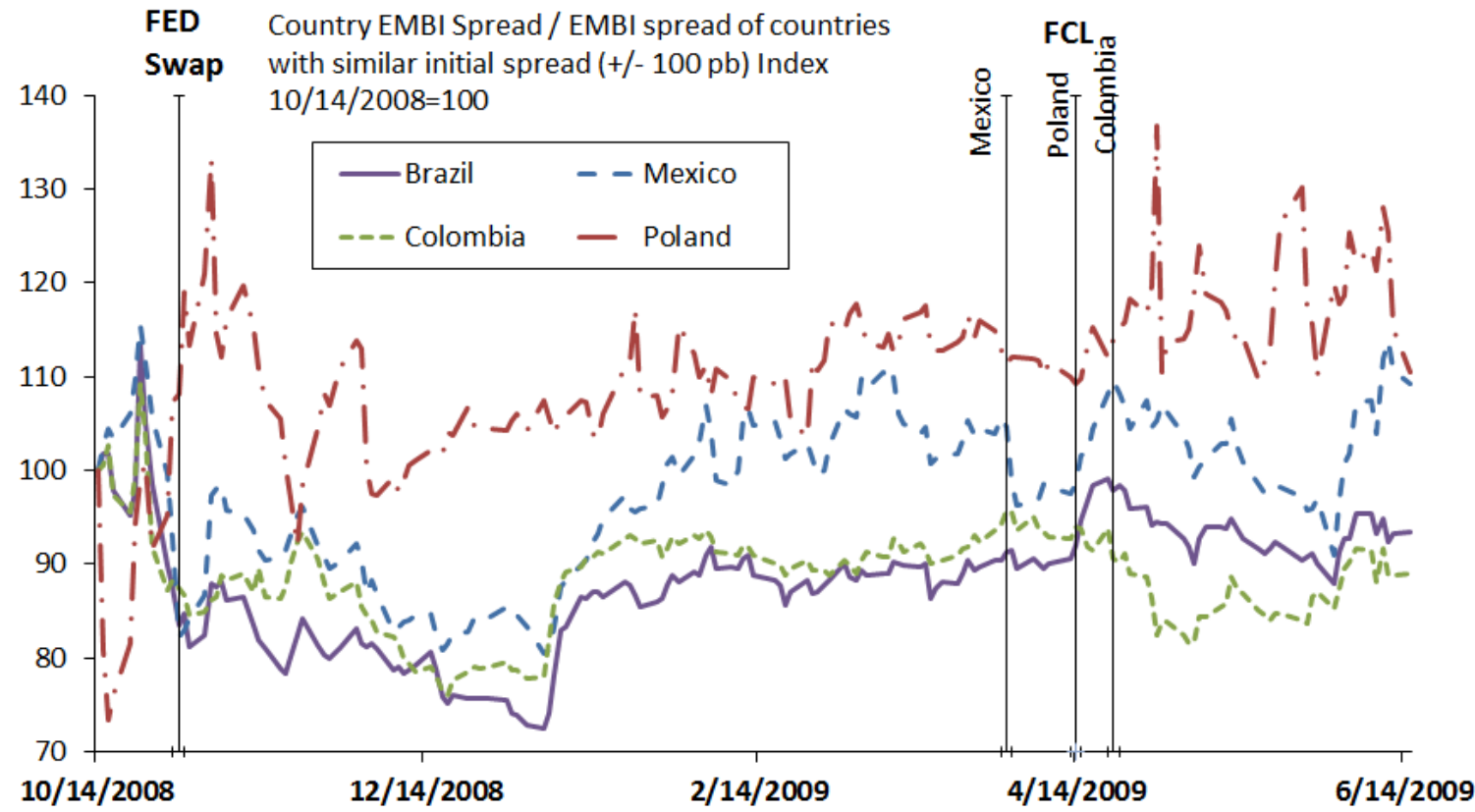

Countries used as controls:

Brazil: $\quad$ Panama, Bulgaria, Egypt, Philippines, Russia, Peru, Turkey, El Salvador, South Africa.

Mexico: Tunisia, Panama, Bulgaria, Egypt, Philippines, Russia, Peru.

Colombia: Panama, Bulgaria, Egypt, Philippines, Russia, Peru, Turkey, El Salvador, South Africa, Uruguay, Lebanon.

Poland: $\quad$ China, Hungary, Malaysia, Chile. 
Figure 3: Performance of countries with and without access facilities around the London Summit

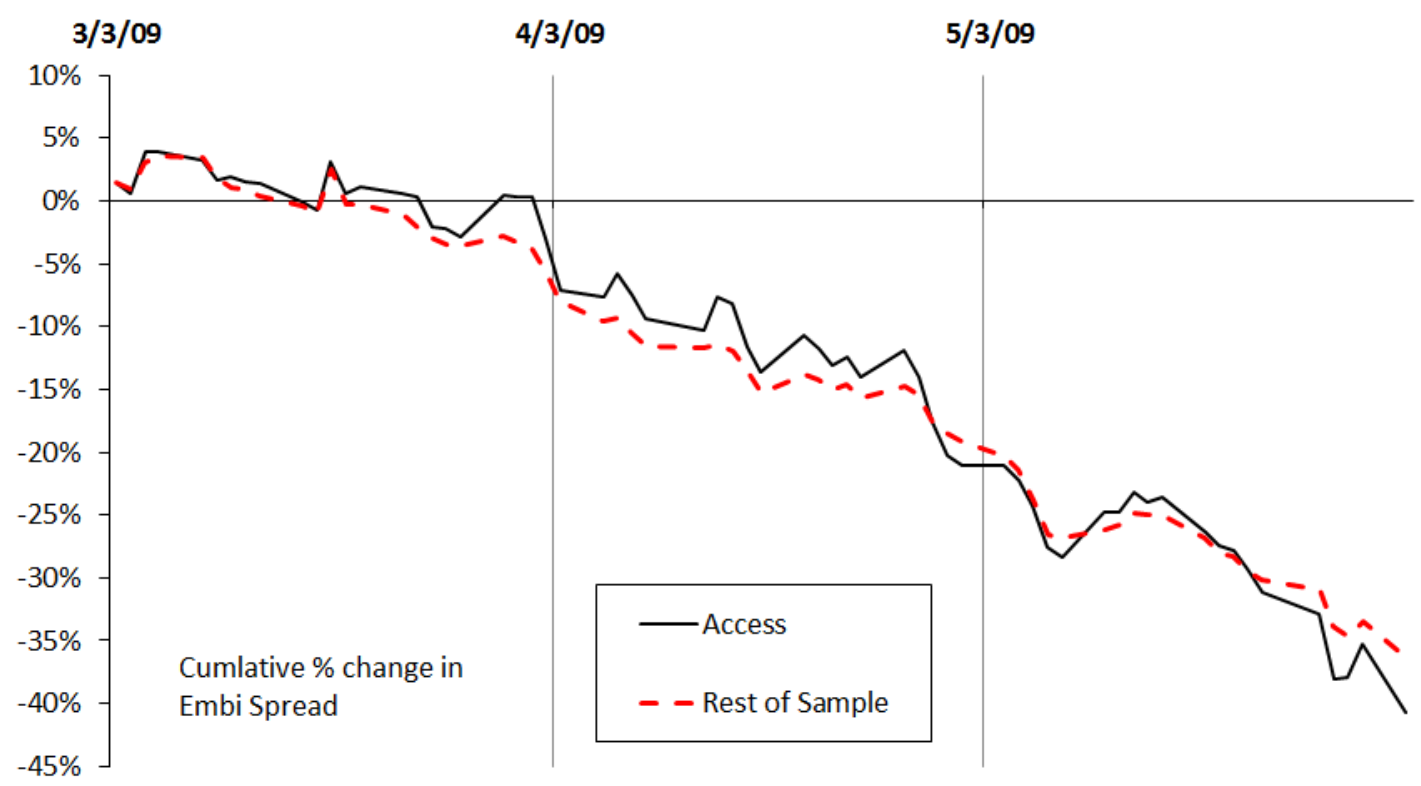

Access is defined as having prior spreads lower than the higher spread among the explictly approved countries.

Access: Brazil, Chile, China, Colombia, Egypt, Malaysia Mexico, Panama, Peru, Phillippines, Poland, South Africa, Tunisia. Rest of Sample: Argentina, Bulgaria, Dominican Republic, Ecuador, El Salvador, Gabon, Georgia, Ghana, Indonesia, , Iraq, Jamaica, Kazakhstan, Lebanon, Pakistan, Russia, Serbia, Sri Lanka, Turkey, Ukraine, Uruguay, Venezuela, Vietnam

Figure 4: International Reserves (\% of World Int. Reserves)

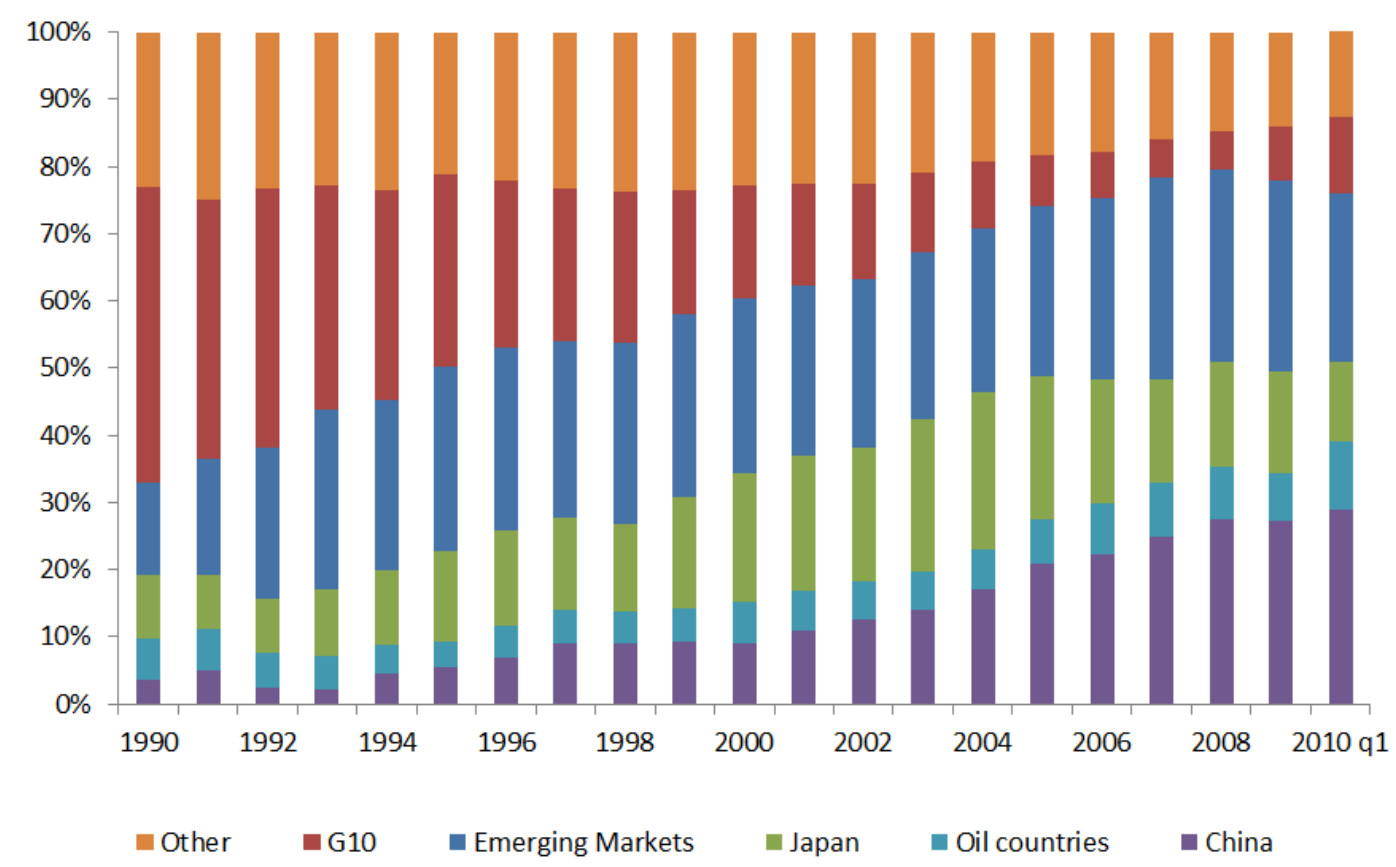


Figure 5.a: FX and CDS spread variance explained by 1st PC

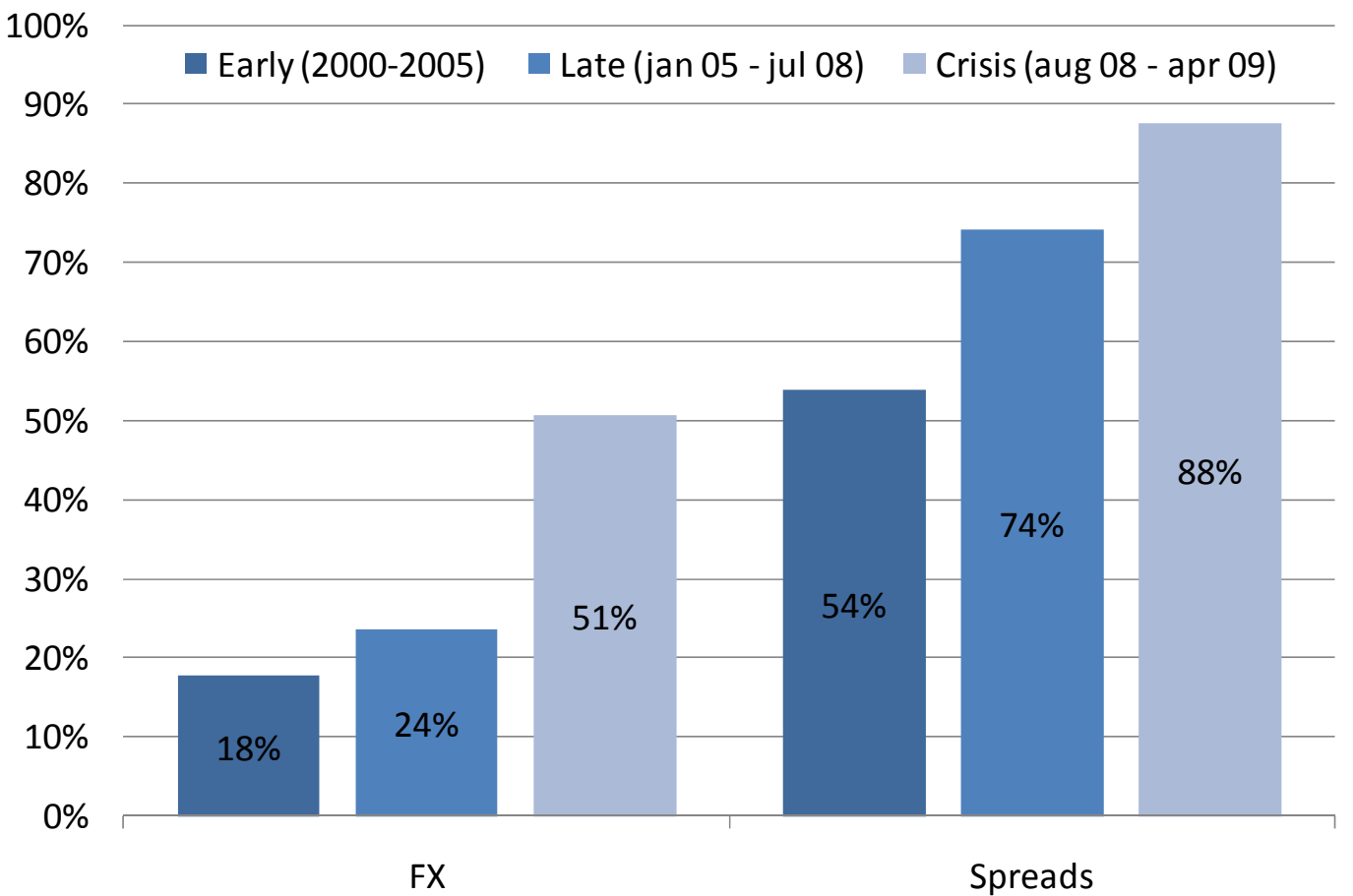

Figure 5.b: FX and CDS spread variability as a function of 1st PC:

Average R2 from country regressions

$100 \%$
$90 \%$
$80 \%$
$70 \%$
$60 \%$
$50 \%$
$40 \%$
$30 \%$
$20 \%$
$10 \%$
$0 \%$

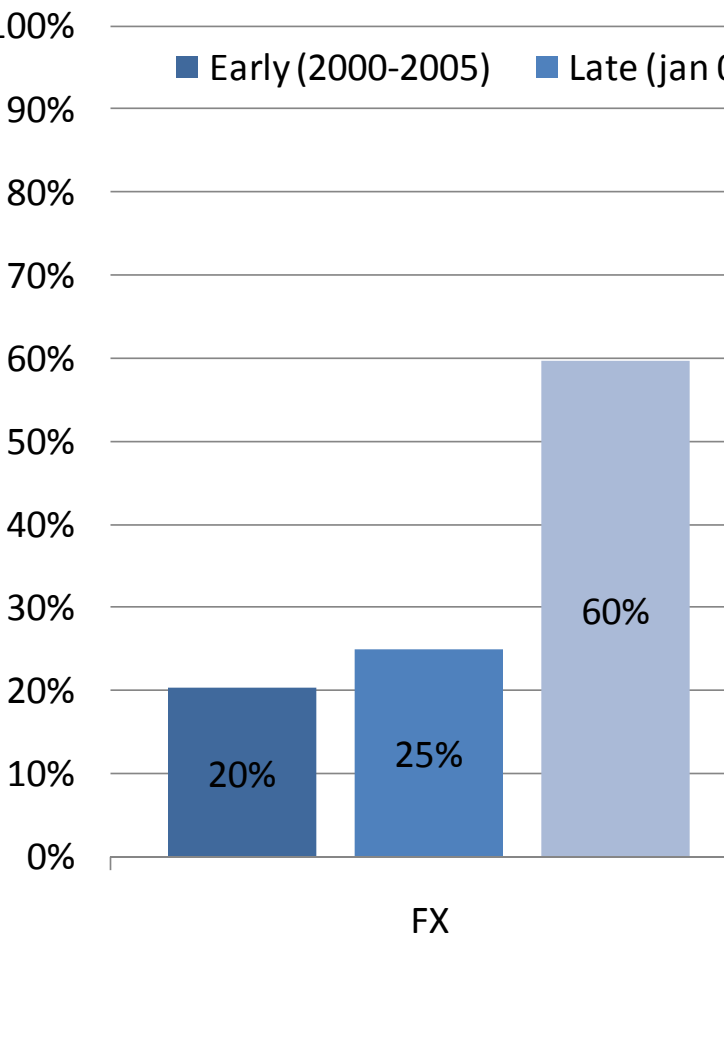

